\title{
Corrigendum: A C-terminal PDZ domain-binding sequence is required for striatal distribution of the dopamine transporter
}

Mattias Rickhag, Freja Herborg Hansen, Gunnar Sørensen, Kristine Nørgaard Strandfelt, Bjørn Andresen, Kamil Gotfryd, Kenneth L. Madsen, Ib Vestergaard Klewe, Ina Ammendrup-Johnsen, Jacob Eriksen, Amy H. Newman, Ernst-Martin Füchtbauer, Jesus Gomeza, David P.D. Woldbye, Gitta Wörtwein \& Ulrik Gether Nature Communications 4:1580 doi: 10.1038/ncomms2568 (2013); Published 12 Mar 2013; Updated 22 Nov 2013

The original version of this Article contained an error in the spelling of the author Ib Vestergaard Klewe, which was incorrectly given as Ib Vestergaard-Klewe. This has now been corrected in both the PDF and HTML versions of the Article. 